\title{
Research of Charging(Discharging) Orderly and Optimizing Load Curve for Electric Vehicles Based on Dynamic Electric Price and V2G
}

\author{
Shuai Yang ${ }^{1, a}$, Zhaowen Luan ${ }^{2}$ and Zhen Qin ${ }^{3}$ \\ 1,2, ${ }^{3}$ Electrical Engineering College, Shandong University, 250061 Jinan, Shandong Province, China
}

\begin{abstract}
Firstly, using the Monte Carlo method and simulation analysis, this paper builds models for the behaviour of electric vehicles, the conventional charging model and the fast charging model. Secondly, this paper studies the impact that the number of electric vehicles which get access to power grid has on the daily load curve. Then, the paper put forwards a dynamic pricing mechanism of electricity, and studies how this dynamic pricing mechanism guides the electric vehicles to charge orderly. Last but not the least, the paper presents a V2G mechanism. Under this mechanism, electric vehicles can charge orderly and take part in the peak shaving. Research finds that massive electric vehicles' access to the power grid will increase the peak-valley difference of daily load curve. Dynamic pricing mechanism and V2G mechanism can effectively lead the electric vehicles to take part in peak-shaving, and optimize the daily load curve.
\end{abstract}

\section{Introduction}

Compared with traditional vehicle, electric vehicle has advantages of low pollution and abundant fuel supply. According to analysis, by 2020 the number of electric vehicle ownership in china will exceed 5 million[1]. Nowadays, many scholars are applying themselves to researching on the subject of large scale of electric vehicles connecting to the power grid[2-5].

This paper is organized as follows. In section II, we use Monte Carlo method to model the conventional charging behaviour of electric vehicles and use analogy simulation to model the fast charging behaviour of electric vehicles. In section III, we propose a kind of dynamic electricity price method which can guide electric vehicles to charge orderly. In section IV, we propose a kind of V2G method which can guide electric vehicles to charge(discharge) orderly. In the last section, we look back the full text and tally up textual point.

\section{Model the Behaviour of Electric Vehicles}

According to the forecast[1], by 2020 the number of electric vehicle ownership in china will exceed 5 million, of which the personal cars are more than 4.3 million, almost $86 \%$ of the total number. Electric vehicles mainly have two kinds of charging models, which are conventional charging model and fast

\footnotetext{
${ }^{\text {a }}$ Corresponding author : jinandiqu@163.com 
charging model. Conventional charging facilities are generally located in residential, corporation, parking lot and so on. In general, charging power of this model is about $10 \mathrm{~kW}$, its charging time is longer and its charging speed is slow. Conventional charging is used to meet the needs of daily use, usually being conducted in the evening or at night. Fast charging facilities are generally located in a special charging station, mainly to meet the needs of temporary charging. Its charging speed is relatively fast and its charging power is about $40 \mathrm{~kW}$. When being charged half an hour in the fast charging station, electric vehicles can drive almost 100 kilometers.

We use the Monte Carlo method and analogy simulation to model the behaviors of electric vehicles.

\subsection{Conventional Charging Modeling}

We use DENZA charging facility in this paper which produces $10 \mathrm{~kW}$ of power. According to related data, we can get the last trip ending and return time distribution probability density[6] and electric vehicle driving distance distribution probability density[7][8]. Continuous charging time is calculated as follow:

$$
t_{i}=\frac{s_{i}}{100 \times\left(p_{c} \times \eta\right)} \times k
$$

$t_{i}$ is the charging time of the $i_{t h}$ datum, $s_{i}$ is the driving distance of the $i_{t h}$ datum. The two share the same distribution probability density. $p_{c}$ is the rated power of charging facility. $\eta=0.9$ is charging efficiency, $k$ is power consumption per hundred kilometers. The $k=18.6 \mathrm{kwh}$ refers to $Q i n$ of $B Y D$. The result are shown in Figure 1 and Figure 2

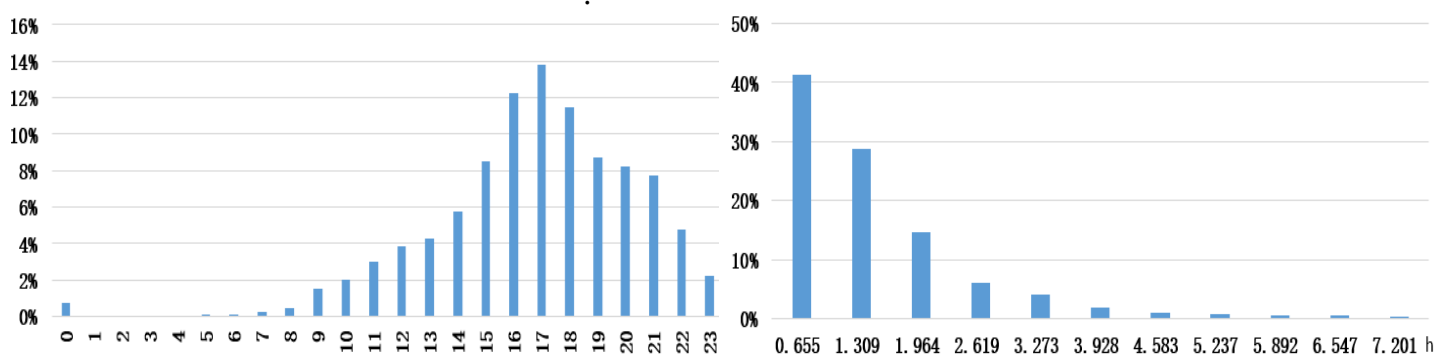

Figure 1. Last trip ending and return time distribution probability density

Figure 2. Continuous charging time distribution probability density

\subsection{Monte Carlo simulation}

Monte Carlo simulation is based on Probability and Mathematical Statistics. Under this method, the problem is solved with a certain probability model, and the approximate solution of the problem is obtained by using large scale simulation[9].

The mathematical and empirical evidence show that the random variables which are influenced by plenty independent homogeneous-small effects are subject to normal distribution. That is to say, if a variable is influenced by many small independent random factors, then it can be considered to be subject to normal distribution. Charging starting time and duration of charging are related to personal preference and mutual independence. Therefore, the charging time of electric vehicle and the duration of charging can be used for the curve fitting of normal distribution[5]. The results of curve fitting are as follows:

$$
\begin{aligned}
& f_{1}(\mathrm{t})=a_{1} \times \exp \left(-\left(\frac{t-b_{1}}{c_{1}}\right)^{2}\right), \mathrm{t} \in[0,24] \\
& f_{2}(\mathrm{t})=a_{2} \times \exp \left(-\left(\frac{t-b_{2}}{c_{2}}\right)^{2}\right), \mathrm{t} \in[0, \infty)
\end{aligned}
$$


$a_{1}=0.1195, b_{1}=17.32, c_{1}=4.721 ; a_{2}=0.5283, b_{2}=-0.3791, c_{2}=2.113 ; 95 \%$ confidence interval. $f_{l}(t)$ is the probability distribution of charging start time, $f_{2}(t)$ is the probability distribution of charging duration. Then daily charging expectation of single electric vehicle can be gotten by Monte Carlo simulation. The calculation is shown in Figure 3 and the result is shown in Figure 4.

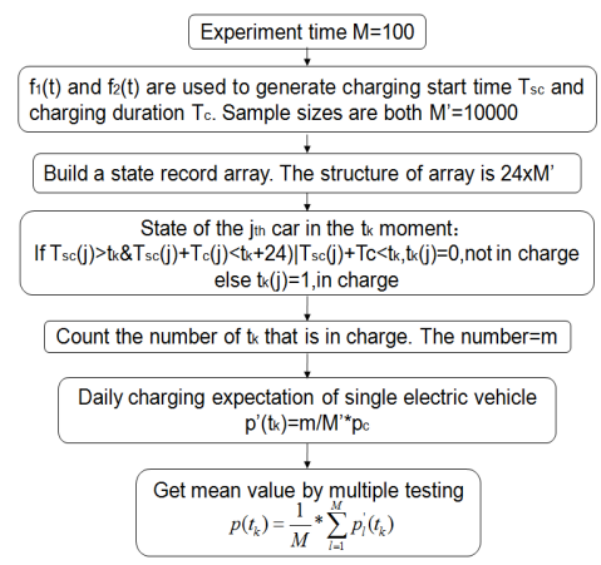

Figure 3. Calculation of Monte Carlo simulation

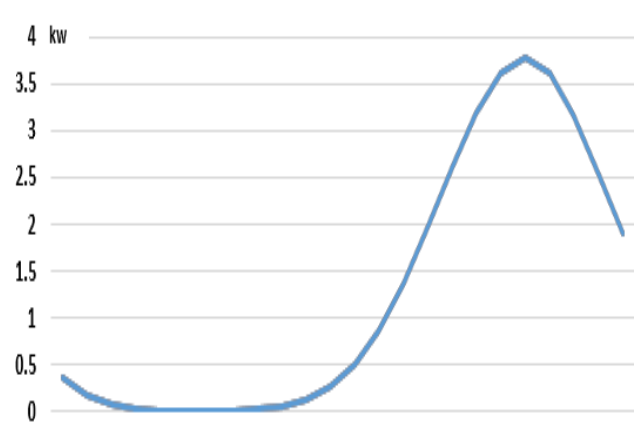

012234567891011121314151617181920212223 Time

Figure 4. Daily load curve of single electric vehicle

\subsection{Fast charging modeling}

Because it is hard to estimate the fast charging behaviour, we get the load curve of fast charging through modeling the business of fast charging station. The vehicle flow of charging station is not the same in different time[10]. The power of charging facility is $40 \mathrm{~kW}$, which is referred to $B Y D$ 's charging facility. The modeling of fast charging behaviour is shown in Table 1.

Table 1. Model of fast charging behavior

\begin{tabular}{|c|c|c|c|c|c|}
\hline \multirow{2}{*}{$\begin{array}{c}\text { Charging } \\
\text { Station } \\
\text { Status }\end{array}$} & $\begin{array}{c}\text { Station } \\
\text { Numbers }\end{array}$ & $\begin{array}{c}\text { Charging Facility } \\
\text { Number in Each Station }\end{array}$ & $\begin{array}{l}\text { Charging } \\
\text { Manners }\end{array}$ & Charging Time per Car & $\begin{array}{c}\text { Business } \\
\text { Hours }\end{array}$ \\
\hline & 220 sites & 5 sites & $\begin{array}{c}1 \text { facility } 1 \\
\text { charging interface }\end{array}$ & $30 \mathrm{~min}$ & $5: 00-24: 00$ \\
\hline \multirow{4}{*}{$\begin{array}{l}\text { Arrival } \\
\text { Interval }\end{array}$} & 5:00-6:00 & 6:00-10:00 & 10:00-14:00 & 14:00-17:00 & 17:00-20:00 \\
\hline & $15 \mathrm{~min}$ & $10 \mathrm{~min}$ & $8 \mathrm{~min}$ & $6 \mathrm{~min}$ & $4 \mathrm{~min}$ \\
\hline & $\begin{array}{l}20: 00- \\
21: 00\end{array}$ & 21:00-22:00 & 22:00-24:00 & & \\
\hline & $6 \mathrm{~min}$ & $10 \mathrm{~min}$ & $15 \mathrm{~min}$ & & \\
\hline
\end{tabular}

According to calculation, the daily load curve of fast charging is obtained as Figure.5.

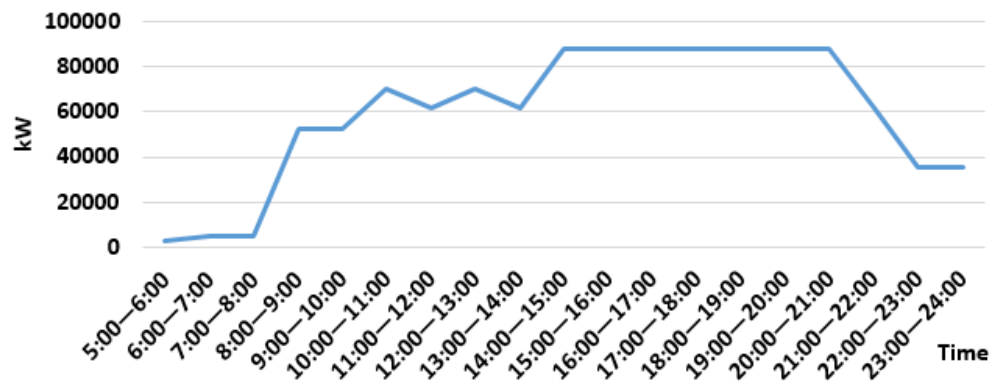

Figure 5. Daily load curve of fast charging

\subsection{Fast charging modeling}


We choose the daily load of a northern city in China as the basic load. When the number of electric vehicles is 100,000, 200,000 and 500,000 respectively, the daily load curves are shown in Figure 6 .

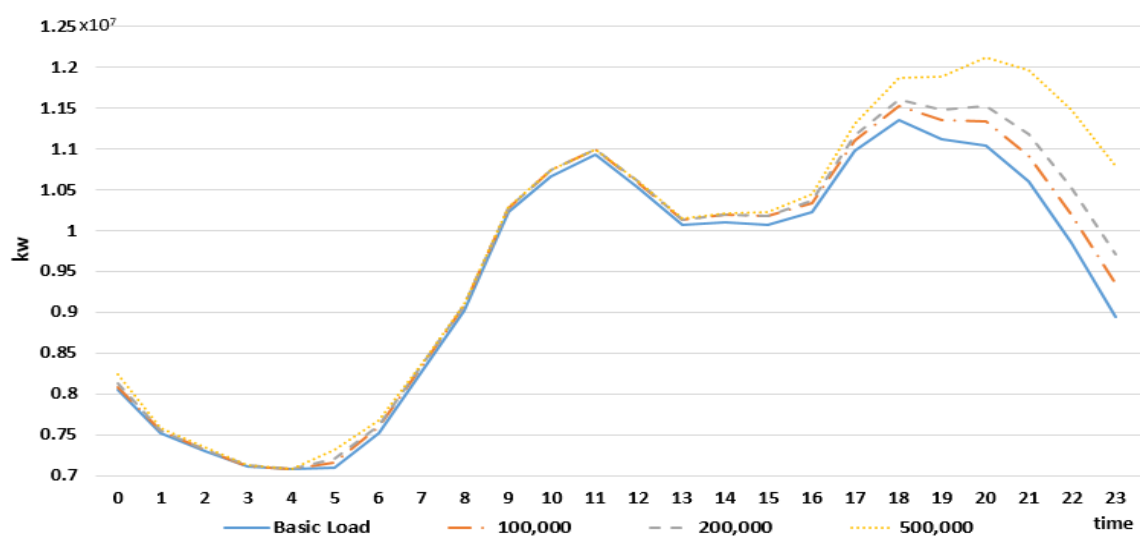

Figure 6. Daily load curve after electric vehicles connecting to the grid

Definite peak valley ratio:

$$
\delta=\frac{\left(P_{\max }-P_{\min }\right)}{P_{\max }} \times 100 \%
$$

In the formulation above, $\delta$ is peak valley ratio, $P_{\max }$ is peak load, $P_{\min }$ is valley load.

Definite peak superposition and valley superposition:

$$
\begin{aligned}
& \gamma_{g}=\frac{\left(p_{\text {min }}^{\prime}-p_{\text {min }}\right)}{p_{\text {min }}} \times 100 \% \\
& \gamma_{f}=\frac{\left(p_{\text {max }}^{\prime}-p_{\text {max }}\right)}{p_{\text {max }}} \times 100 \%
\end{aligned}
$$

In the formulations above, $\gamma_{g}$ and $\gamma_{f}$ are peak superposition and valley superposition respectively. $p^{\prime}{ }_{\text {min }}$ is valley load which contains both basic load and electric vehicle load; $p^{\prime}{ }_{\max }$ is peak load which contains both basic load and electric vehicle load. $p_{\min }$ is basic valley load and $p_{\max }$ is basic peak load. The result of calculation about load curve that electric vehicles connect to the grid is shown in Table 2 .

Table 2. The calculation about the electric vehicles connecting to the grid

\begin{tabular}{cccccc}
\hline & $\mathbf{p}_{\text {min }}^{\prime}(\mathbf{M W})$ & $\boldsymbol{\gamma}_{\mathrm{g}}$ & $\mathbf{p}_{\text {max }}^{\prime}(\mathbf{M W})$ & $\boldsymbol{\gamma}_{\mathbf{f}}$ & \multicolumn{1}{c}{$\boldsymbol{\delta}$} \\
\hline Basic Load & 7,075 & 0 & 11,350 & $1.544 \%$ & $38.60 \%$ \\
\hline $\mathbf{1 0 0 , 0 0 0}$ & $7,076.82$ & $0.03 \%$ & $11,525.23$ & $1.62 \%$ & $38.63 \%$ \\
\hline $\mathbf{2 0 0 , 0 0 0}$ & $7,078.72$ & $0.05 \%$ & $11,534.14$ & $15.03 \%$ & $45.74 \%$ \\
\hline $\mathbf{5 0 0 , 0 0 0}$ & $7,084.3$ & $0.13 \%$ & $13,056.35$ & 0 \\
\hline
\end{tabular}

According to Figure. 6 and Table.2, the load characteristics of electric vehicles are similar to the city's electricity load characteristics. The reason is that most users tend to charge electric vehicles after stopping work and arriving at home in the evening in the meanwhile the charging period is also the peak period. This characteristic makes the difference between peak load and valley load bigger. In addition, it can be inferred from Figure. 1 and Figure. 2 that the electric vehicle is usually used as a tool replacing the foot, so the driving distance is not so long. This characteristic makes it unavailable to fill the valley by charging in the midnight. The characteristics discussed above may waste the power, increase the power loss and increase the burden of power grid. From what has been discussed above, we may safely arrive at the conclusion that due attention has to be paid to guide the charging behaviors of electric vehicles. 


\section{Dynamic Power Price}

Different power prices in different time can guide charging behaviors of electric vehicles. When the price is high, users tend to charge at other times. Conversely, when the price is low, users tend to charge in this time. The price elasticity function can explain this phenomenon:

$$
\varepsilon=\frac{\Delta D_{t} / D_{t}}{\Delta C_{t} / C_{t}}
$$

In formulation(7), $\varepsilon$ is price elasticity index; $\Delta D_{t}$ and $\Delta C_{t}$ are demand changes and price changes respectively in $t_{t h}$ moment; $D_{t}$ and $\Delta C_{t}$ are demand and price in $t_{t h}$ moment.

In this paper, one day is separated into 24 electric price ranges. Each range starts at the beginning of this hour and the price continues one hour. The electric price of each range is related to the total load of this range and the mean load of the whole day. The models are as follows:

$$
\begin{gathered}
D_{t}^{\prime}=D_{t}+\Delta D_{t} \\
\Delta D_{t}=D_{t} \times \frac{\Delta C_{t}}{C_{t}} \times \varepsilon \\
\frac{\Delta C_{t}}{C_{t}}=\frac{D_{t}-\bar{D}}{D_{t}} \\
\bar{D}=\sum_{t=1}^{T} D_{t}
\end{gathered}
$$

$D_{t}^{\prime}$ is the load adjusted by dynamic electric price, $\bar{D}$ is the mean demand of the day, $T$ is the time range, $\varepsilon=-0.3[11]$, the number of electric vehicles connecting to power grid is 500,000. Comparison of load curves before and after being adjusted by dynamic electric price are shown in Figure 7 and Table 3.

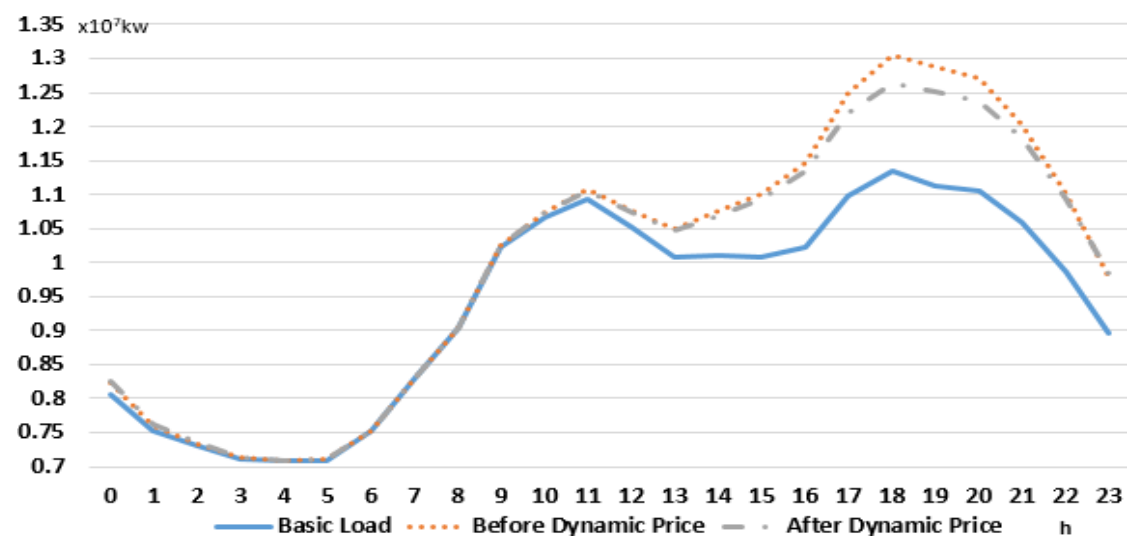

Figure 7. The effect of dynamic electric price 1

Table 3. The effect of dynamic electric price 2

\begin{tabular}{cccc}
\hline & $\gamma_{\mathrm{g}}$ & $\gamma_{\mathrm{f}}$ & $\boldsymbol{\delta}$ \\
\hline Basic Load & 0 & 0 & $37.67 \%$ \\
\hline Before Dynamic Price & $0.131 \%$ & $15.030 \%$ & $45.74 \%$ \\
\hline After Dynamic Price & $0.117 \%$ & $11.381 \%$ & $43.97 \%$ \\
\hline
\end{tabular}

It can be seen from Figure. 7 and Table. 3 that load curve condition is improved by dynamic electric price. Under this dynamic electric price, although $\gamma_{g}$ has a little decrease, $\gamma_{f}$ has a significant reduction. $\gamma_{f}$ decreases from $15.030 \%$ to $11.381 \%$, having $3.649 \%$ fall. In addition $\delta$ decreases from $45.74 \%$ to $43.97 \%$, having $1.77 \%$ fall. So it can be concluded that it is useful for this dynamic electric price to guide the charging behaviors of electric vehicles and smooth the load curve. 


\section{V2G Regulation}

Vehicle to Grid is called V2G for short[12]. V2G describes a system where plug-in electric vehicles communicate with the electric power grid to sell demand response[13]. Hence, V2G application is transformational and revolutionary in that it precipitates the confluence of transportation and electric power system, thereby introducing electricity as a meaningful automotive fuel[14]. Under V2G regulation, electric vehicles require charging and discharging batteries.

Its model is as followed:

- The electric vehicle can obtain power from power grid when it need to charge;

- The electric vehicle can release power energy to power grid when it need to discharge.

It can be inferred from Figure. 1 and Figure. 2 that most users drive their electric vehicles not so far. So their charging time is not so long. Charging time is less than 4 hours in a day for most users. It means that when the battery is full, there will be a long time without any activities for electric vehicles. The free time can be used to fill the valley of load curve in order to reduce the burden of power grid and conserve the energy. Under $\mathrm{V} 2 \mathrm{G}$ regulation, electric vehicles are discharged in peak period and charged in valley period.

Based on Figure.1, Figure.7 and the experience, the users who get home from 16:00pm to 23:00pm can be regarded as main force to participate in $\mathrm{V} 2 \mathrm{G}$ program. Referring to the step electric price mechanism of Beijing[15], we set the peak load period from 18:00pm to 23:00pm and the valley load period from 23:00pm to 7:00am. Under the prerequisite of fully charging in electric vehicles, the cars participating in $\mathrm{V} 2 \mathrm{G}$ program discharge in peak load period and charge in valley load period. The main mission of V2G program set by us in this paper is to clip the peak load and fill the valley load. The car that begins to discharge in $i$ o'clock. The model is as follows:

$$
\begin{aligned}
t_{f i} & \rightarrow \max \\
T_{i}+2 t_{f i}+t_{c i} & \leq(24-23+7) \\
0 \leq t_{f i} & \leq(23-16)
\end{aligned}
$$

$t_{f i}$ is the maximum discharging time of electric vehicles that begin to discharge in $i$ o'clock, $t_{c i}$ is the charging time of electric vehicles which begin to discharge in $i$ o'clock. After calculation, the maximum discharging time of electric vehicles that begin to discharge in $i$ o'clock is shown in Table 5.

Table 4. Maximum discharging time

\begin{tabular}{ccccccccc}
\hline & $\mathbf{0 . 6 5 5 h}$ & $\mathbf{1 . 3 0 9 h}$ & $\mathbf{1 . 9 6 4 h}$ & $\mathbf{2 . 6 1 9 h}$ & $\mathbf{3 . 2 7 3 h}$ & $\mathbf{3 . 9 2 8 h}$ & $\mathbf{4 . 5 8 3 h}$ & $\mathbf{5 . 2 3 7 h}$ \\
\hline $\mathbf{1 6 : 0 0}$ & $7 \mathrm{~h}$ & $6.691 \mathrm{~h}$ & $6.036 \mathrm{~h}$ & $5.381 \mathrm{~h}$ & $4.727 \mathrm{~h}$ & $4.072 \mathrm{~h}$ & $3.417 \mathrm{~h}$ & $2.763 \mathrm{~h}$ \\
\hline $\mathbf{1 7 : 0 0}$ & $6 \mathrm{~h}$ & $6 \mathrm{~h}$ & $6 \mathrm{~h}$ & $5.381 \mathrm{~h}$ & $4.727 \mathrm{~h}$ & $4.072 \mathrm{~h}$ & $3.417 \mathrm{~h}$ & $2.763 \mathrm{~h}$ \\
\hline $\mathbf{1 8 : 0 0}$ & $5 \mathrm{~h}$ & $5 \mathrm{~h}$ & $5 \mathrm{~h}$ & $5 \mathrm{~h}$ & $4.727 \mathrm{~h}$ & $4.072 \mathrm{~h}$ & $3.417 \mathrm{~h}$ & $2.763 \mathrm{~h}$ \\
\hline $\mathbf{1 9 : 0 0}$ & $4 \mathrm{~h}$ & $4 \mathrm{~h}$ & $4 \mathrm{~h}$ & $4 \mathrm{~h}$ & $4 \mathrm{~h}$ & $4 \mathrm{~h}$ & $3.417 \mathrm{~h}$ & $2.763 \mathrm{~h}$ \\
\hline $\mathbf{2 0 : 0 0}$ & $3 \mathrm{~h}$ & $3 \mathrm{~h}$ & $3 \mathrm{~h}$ & $3 \mathrm{~h}$ & $3 \mathrm{~h}$ & $3 \mathrm{~h}$ & $3 \mathrm{~h}$ & $2.763 \mathrm{~h}$ \\
\hline $\mathbf{2 1 : 0 0}$ & $2 \mathrm{~h}$ & $2 \mathrm{~h}$ & $2 \mathrm{~h}$ & $2 \mathrm{~h}$ & $2 \mathrm{~h}$ & $2 \mathrm{~h}$ & $2 \mathrm{~h}$ & $2 \mathrm{~h}$ \\
\hline $\mathbf{2 2 : 0 0}$ & $1 \mathrm{~h}$ & $1 \mathrm{~h}$ & $1 \mathrm{~h}$ & $1 \mathrm{~h}$ & $1 \mathrm{~h}$ & $1 \mathrm{~h}$ & $1 \mathrm{~h}$ & $1 \mathrm{~h}$ \\
\hline
\end{tabular}

In Table 4, the first row represents duration and the first column represents starting time.

Definition: $a_{i j}$ is the discharging element exiting in Table.5. $i$ is the beginning time of discharging, $\mathrm{j}$ is the duration of charging. The total number of electric vehicle accessing the grid is $A=500,000, p_{i}$ is the probability of charging in $i$ o'clock, $q_{j}$ is the probability of that electric vehicle charge for $\mathrm{j}$ hour(s), $\mathrm{D}_{\mathrm{i}}$ is the power that is injected to the grid by electric vehicles in $i$ o'clock. Search the $a_{i j}$ above the Table. 5 one by one and calculate the total contribution every $a_{i j}$ makes to $\mathrm{D}_{\mathrm{i}}$. Sum of $\mathrm{D}_{\mathrm{i}}$ is the power injection. The calculation and results are shown in Figure. 8 and Table 5 respectively. 

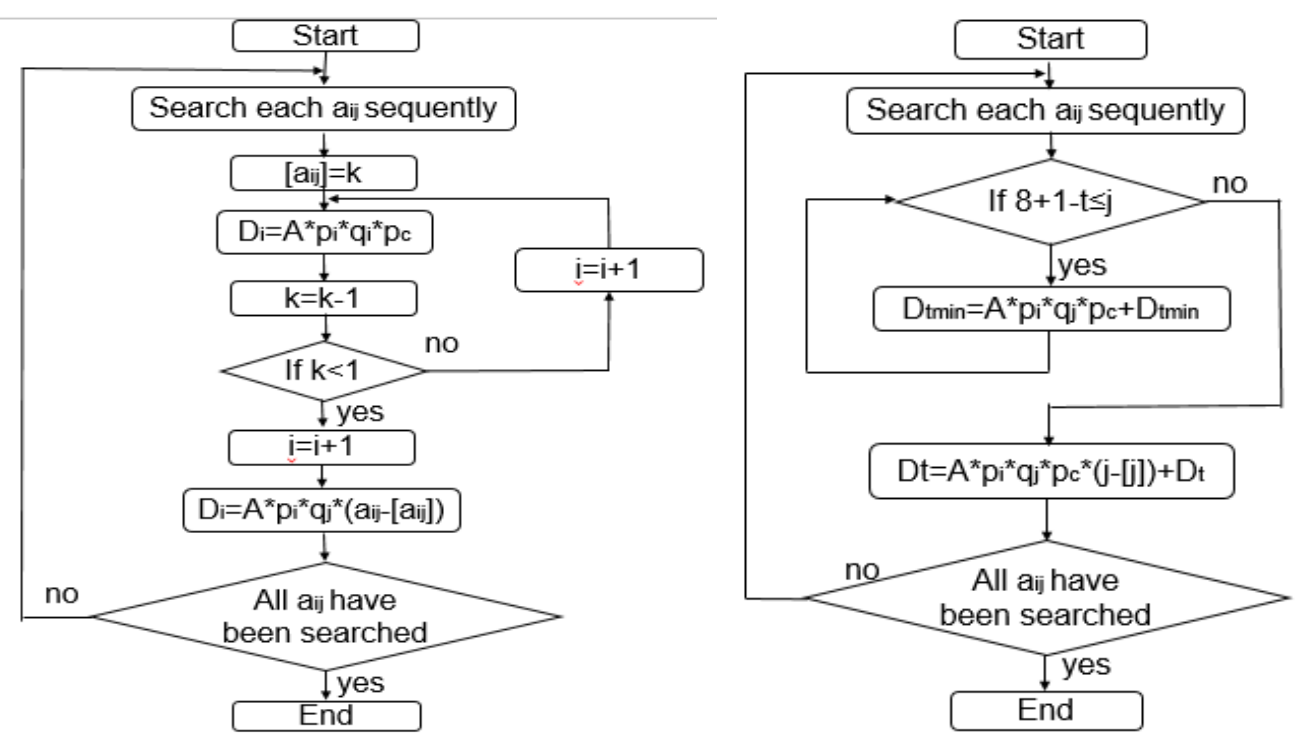

Figure 8. The calculation of discharging

Figure 9. The calculation of charging

Table 5.Power of discharging

\begin{tabular}{|c|c|c|c|c|c|c|c|}
\hline & $16: 00-17: 00$ & $\begin{array}{r}17: 00- \\
18: 00 \\
\end{array}$ & $\begin{array}{r}18: 00- \\
19: 00 \\
\end{array}$ & 19:00-20:00 & 20:00-21:00 & 21:00-22:00 & 22:00-23:00 \\
\hline $16: 00$ & $611,750 \mathrm{kw}$ & $611,750 \mathrm{kw}$ & $610,552 \mathrm{kw}$ & $603,465 \mathrm{kw}$ & $584,159 \mathrm{kw}$ & $542,239 \mathrm{kw}$ & $377,856 \mathrm{kw}$ \\
\hline 17:00 & & $690,000 \mathrm{kw}$ & $690,000 \mathrm{kw}$ & $688,649 \mathrm{kw}$ & $680,656 \mathrm{kw}$ & $658,880 \mathrm{kw}$ & $601,186 \mathrm{kw}$ \\
\hline $18: 00$ & & & $575,000 \mathrm{kw}$ & $575,000 \mathrm{kw}$ & $573,874 \mathrm{kw}$ & $567,213 \mathrm{kw}$ & $540,390 \mathrm{kw}$ \\
\hline 19:00 & & & & $437,500 \mathrm{kw}$ & $437,500 \mathrm{kw}$ & $436,643 \mathrm{kw}$ & $431,575 \mathrm{kw}$ \\
\hline 20:00 & & & & & $412,500 \mathrm{kw}$ & $412,500 \mathrm{kw}$ & $387,500 \mathrm{kw}$ \\
\hline 21:00 & & & & & & $387,500 \mathrm{kw}$ & $387,500 \mathrm{kw}$ \\
\hline 22:00 & & & & & & & $237,500 \mathrm{kw}$ \\
\hline
\end{tabular}

In Table 5, the first row represents the time period of discharging and the first column represents the start time of discharging.

After getting $t_{f i}$ and $t_{c i}$, we can calculate $t_{c i}^{\prime}$, the value of charging time in valley load period.

$$
t_{c i}^{\prime}=t_{f i}+t_{c i}
$$

We separate the valley load period into 8 time periods. Each $a_{i j}$ select one period that has the minimum load. Generally speaking, from 23:00-7:00, the later time is, the lower the loads are. So the charging rule we propose is that charging in later time period is prior than charging in the early time period. If $a_{i j}$ can charges only $1.3 \mathrm{~h}$, for example, it charges $1 \mathrm{~h}$ in the time period of 6:00-7:00 and charges $0.3 \mathrm{~h}$ in the time period of 5:00-6:00. In other words, it charges from 6:00 to 7:00 at rated power and charges from 5:00 to 6:00 at 30\% rated power. The calculation of charging is shown in Figure.9 and Table 6.

Table 6. Power of charging

\begin{tabular}{ccccccccc}
\hline & $\begin{array}{c}\mathbf{2 3 : 0 0} \\
\mathbf{0 : 0 0}\end{array}$ & $\mathbf{0 : 0 0 - 1 : 0 0}$ & $\mathbf{1 : 0 0 - 2 : 0 0}$ & $\mathbf{2 : 0 0 - 3 : 0 0}$ & $\mathbf{3 : 0 0 - 4 : 0 0}$ & $\mathbf{4 : 0 0 - 5 : 0 0}$ & $\mathbf{5 : 0 0 - 6 : 0 0}$ & $\mathbf{6 : 0 0 - 7 : 0 0}$ \\
\hline $\mathbf{1 6 : 0 0}$ & 524,536 & 611,750 & 611,750 & 611,750 & 611,750 & 611,750 & 611,750 & 611,750 \\
\hline $\mathbf{1 7 : 0 0}$ & 263,811 & 591,630 & 690,000 & 690,000 & 690,000 & 690,000 & 690,000 & 690,000 \\
\hline
\end{tabular}




\begin{tabular}{ccccccccc}
\hline $\mathbf{1 8 : 0 0}$ & 54,871 & 219,842 & 493,025 & 575,000 & 575,000 & 575,000 & 575,000 & 575,000 \\
\hline $\mathbf{1 9 : 0 0}$ & 19,731 & 49,711 & 160,669 & 375,128 & 437,500 & 437,500 & 437,500 & 437,500 \\
\hline $\mathbf{2 0 : 0 0}$ & 5,586 & 18,604 & 46,870 & 151,488 & 353,692 & 412,500 & 412,500 & 412,500 \\
\hline $\mathbf{2 1 : 0 0}$ & 758 & 5,247 & 17,476 & 44,029 & 142,307 & 332,256 & 387,500 & 387,500 \\
\hline $\mathbf{2 2 : 0 0}$ & 0 & 464 & 3,216 & 10,711 & 26,985 & 87,220 & 203,640 & 237,500 \\
\hline
\end{tabular}

Based on Figure 8, Figure 9, Table 5 and Table 6, we can get the daily load curve adjusted by dynamic electric price and V2G. The comparison between load curve and load curve adjusted by dynamic electric price and V2G is shown in Figure.10 and Table 7. The number of electric vehicles connecting the grid is 500,000 .

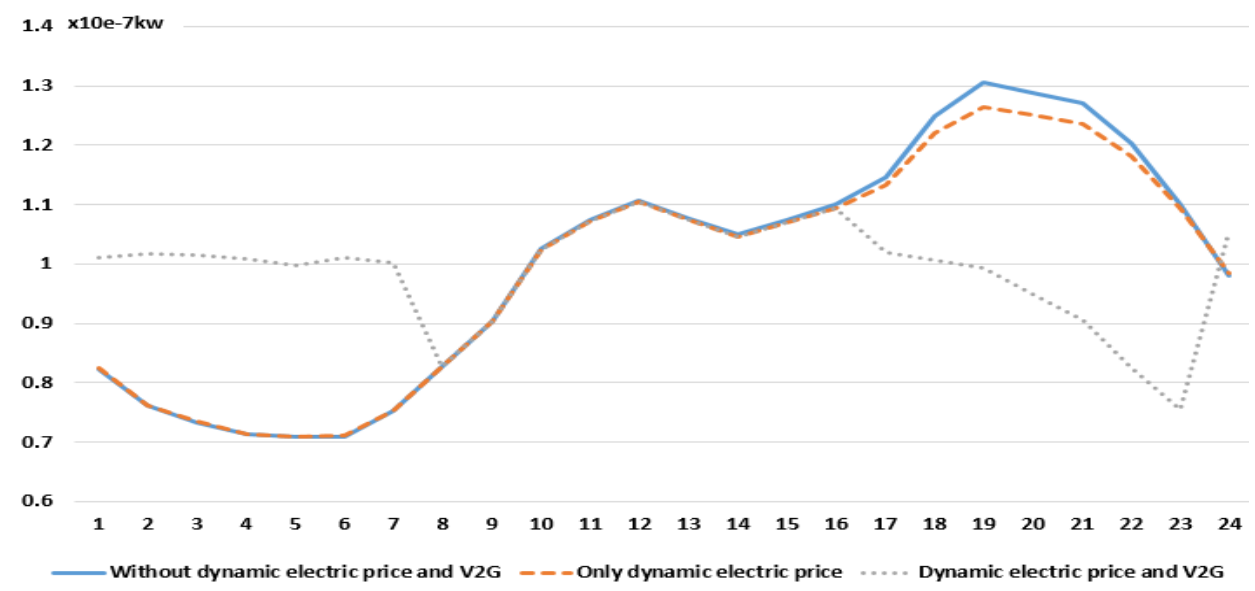

Figure 10. The effects of $\mathrm{V} 2 \mathrm{G}$ and dynamic electric price 1

Table 7. The effects of $\mathrm{V} 2 \mathrm{G}$ and dynamic electric price 2

\begin{tabular}{cccccc}
\hline & Valley Time & $\mathbf{p}_{\text {min }}^{\prime}$ & Peak Time $^{\prime}$ & $\mathbf{p}_{\max }$ & $\boldsymbol{\delta}$ \\
\hline No dynamic electric price & $4: 00-5: 00$ & $7081 \mathrm{MW}$ & $18: 00-19: 00$ & $13056 \mathrm{MW}$ & $45.76 \%$ \\
\hline Only dynamic electric price & $4: 00-5: 00$ & $7083 \mathrm{MW}$ & $18: 00-19: 00$ & $12642 \mathrm{MW}$ & $43.97 \%$ \\
\hline Dynamic electric price and V2G & $22: 00-23: 00$ & $7553 \mathrm{MW}$ & $11: 00-12: 00$ & $11046 \mathrm{MW}$ & $31.62 \%$ \\
\hline
\end{tabular}

It can be known from Figure.10, and Table.7 that the method of $\mathrm{V} 2 \mathrm{G}$ is valuable for improvement of power load characteristics. But it should be noticed that the valley time has been changed after V2G method adopted. If the number of electric vehicles remain elevated, V2G maybe be not enough. The problems will be more complicated. If we just make use of V2G simply when the number of electric vehicles is large enough, the new valley load period may appear.

\section{Conclusion}

When the number of electric vehicles connecting to power grid is small, the influence to the grid is limited. When the number of electric vehicles connecting power grid is big, the influence to the grid is tremendous. Dynamic electric price is available to optimize the daily load curve. It can guide electric vehicle users to charge their cars orderly. V2G is more useful to optimize the daily load curve. It allows users of electric vehicles to participate in peak/valley load regulating of power system. But it should be noticed that the valley time has been changed after V2G method being adopted. If the number of electric vehicles remain elevated, $\mathrm{V} 2 \mathrm{G}$ will be not enough. If we just make use of V2G simply when the number of electric vehicles is large enough, the new valley load period may appear.

Many problems still need to be further studied, such as charging/discharging period segmentation, the subsidy rule to V2G users, coordination between renewable energy and electric vehicles and so on. 


\section{References}

1. "Electric Vehicle Charging Infrastructure Development Guide (2015-2020)", China National Development and Reform Commission,2015:3-5.

2. Lopes, J.A.P.; Soares, F.J.; Almeida, P.M.R., "Integration of Electric Vehicles in the Electric Power System," in Proceedings of the IEEE, vol.99, no.1, pp.168-183, Jan. 2011

3. Madawala, U.K.; Thrimawithana, D.J., "A Bidirectional Inductive Power Interface for Electric Vehicles in V2G Systems," in Industrial Electronics, IEEE Transactions on, vol.58, no.10, pp.4789-4796, Oct. 2011

4. Rahman, S.; Shrestha, G.B., "An investigation into the impact of electric vehicle load on the electric utility distribution system," in Power Delivery, IEEE Transactions on, vol.8, no.2, pp.591-597, Apr 1993

5. Shaoyun Ge; Liang Feng; Hong Liu, "The planning of electric vehicle charging station based on Grid partition method," in Electrical and Control Engineering (ICECE), 2011 International Conference on, vol., no., pp.2726-2730, 16-18 Sept. 2011

6. A. M. William and A. M. Martin, "Travel estimation techniques for urban planning," Transport Research Board National Research Council, U.S., NCHRP 365 Rep. B8-29.6,1998.[online]. Available: http://ntl.bts.gov/lib/21000/21500/21563/PB99126724.pdf.

7. Taylor M J, Alexander A. Evaluation of the impact of plug-in electric vehicle loading on distribution system operations. IEEE Power \& Energy Society General Meeting, Calgary, Canada, 2009: 1-6.

8. Vyas A, Santini D. Use of national surveys for estimation 'full' PHEV potential for oil user reduction, 2008-07-21. Available: http://www.transportation.anl.gov/pdfs/HV/525.pdf.

9. Xiao Gang, "Monte Carlo method in system reliability analysis", published by Science Press,2003.

10. Bai Gaoping, "Research on the Adaptability of Large-scale Electric Vehicle Charging(discharging) Stations and the Grid", Master's thesis , Beijing Jiaotong University, 2011.

11. Lamont, J.W.; Obessis, E.V., "Emission dispatch models and algorithms for the 1990s," in Power Systems, IEEE Transactions on, vol.10, no.2, pp.941-947, May 1995.

12. Chukwu, U.C.; Mahajan, S.M., "V2G electric power capacity estimation and ancillary service market evaluation," in Power and Energy Society General Meeting, 2011 IEEE , vol., no., pp.1-8, 24-29 July 2011.

13. Available: http://en.wikipedia.org/wiki/Vehicle-to-grid

14. Chukwu, U.C.; Mahajan, S.M.; Spina, I.; Rizzo, R., "A nomogram for estimating energy loss in a distribution network due to penetration of V2G," in Clean Electrical Power (ICCEP), 2013 International Conference on, vol., no., pp.476-481, 11-13 June 2013.

15. National Development and Reform Commission, "Notice of the national development and Reform Commission on the implementation of the linkage of coal and electricity prices in North China Power Grid", China public document,2005. 